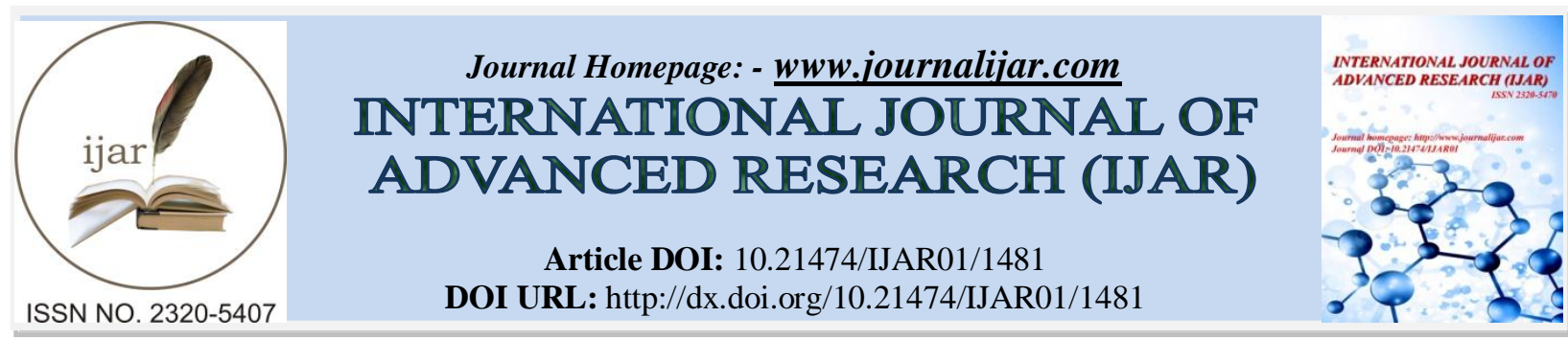

RESEARCH ARTICLE

\title{
CHECKING THE PURITY OF WATER SAMPLES COLLECTED FROM A RURAL AREA AND ASSURING THE PUBLIC SAFETY BY CREATING AWARENESS TO THE PEOPLE LIVING IN THAT AREA.
}

Priya Prakash and Deepalakshmi K.

Asst. Professor (contract basis) SSV College, Ernakulam.

\section{Manuscript Info}

Manuscript History

Received: 12 July 2016

Final Accepted: 18 August 2016

Published: September 2016

Key words:-

TDS, DO, BOD, COD, SPC, MPN,

IMViC, E.coli, ISI, CPCB etc.

\section{Abstract}

Water is the basic and primary need of all vital organisms. It plays a significant role for the sound health of all living organism including plant and animal life. Polluted water (containing solids and dissolved organic compounds) serves as an excellent medium for the growth and multiplication of microorganisms and it also impart offensive odour to the water. With the increasing industrialization and population growth water sources and its availability for various purposes such as drinking, recreation, aquaculture, agriculture, have been adulterated with industrial as well as animal and human wastes. The organisms typically found in different types of water belong to fungi, protozoa, algae, bacteria, actinomycetes and viruses for example, the causative agents of dysentery, typhoid, cholera, giardiasis, hepatitis etc. Sewage consists of $99.9 \%$ water and $0.02-0.03 \%$ suspended solids and other organic and inorganic matters. The following techniques were conducted respectively to check the purity of the water samples taken from different places of a rural area. TDS was determined as the residue left after evaporation of the filtered sample. DO in the water sample was determined using titrimetric method. BOD, which is used as a parameter to express the strength of sewage by measuring the volume of oxygen required by bacteria to metabolize the organic compounds in sewage, was determined. COD, another technique which is more efficient to estimate the organic matter in water by using the oxidability of organic matter by a chemical oxidant such as potassium permanganate or potassium dichromate was determined. Acidity, Alkalinity and Chlorine content of each sample was also determined. SPC was done, which is one of the routine procedures to determine the number of microbes in water. The purity of drinking water was evaluated by testing for the presence of coliforms, which is an indicator of fecal contaminations. It was done by using MPN analysis. Detection and confirmation of the presence of E.coli was done by using IMViC test. Rapid methods to detect E. coli are important to identify the source of outbreaks and to assure public safety. The overall results were compared with ISI specification and CPCB standard values for the discharge of treated water. 


\section{Introduction:-}

Water is the basic and primary need of all vital organisms. It plays a significant role for the sound health of all living organism including plant and animal life. About $75 \%$ of the earth's crust is covered with water and the human body comprises approximately $70 \%$ of water. Therefore, water is most urgent for life and essential for good health of human beings. With the increasing industrialization and population growth water sources and its availability for various purposes such as drinking, recreation, aquaculture, agriculture, have been adulterated with industrial as well as animal and human wastes. Polluted water (containing solids and dissolved organic compounds) serves as an excellent medium for the growth and multiplication of microorganisms and it also impart offensive odour to the water.

The organisms typically found in different types of water belong to fungi, protozoa, algae, bacteria, actinomycetes and viruses for example, the causative agents of dysentery, typhoid, cholera, giardiasis, hepatitis etc. Sewage consists of $99.9 \%$ water and $0.02-0.03 \%$ suspended solids and other organic and inorganic matters. Standard plate count method is one of the routine procedures to determine the number of microbes in water. BOD (Biological Oxygen Demand) is the other procedure which is used as a parameter to express the strength of sewage by measuring the volume of oxygen required by bacteria to metabolize the organic compounds in sewage. COD (Chemical Oxygen Demand) another technique which is more efficient to estimate the organic matter in water by using the oxidability of organic matter by a chemical oxidant such as potassium permanganate or potassium dichromate. The purity of drinking water is evaluated by testing for the presence of coliforms, which is an indicator of fecal contaminations. It can be done by using MPN (Multiple Tube Fermentation) analysis. Majority of the bacteria coliform are present in large numbers among the intestinal flora of humans and other warm-blooded animals, and are thus found in faecal wastes. As a consequence, coliforms, detected in higher concentrations than pathogenic bacteria, are used as an index of the potential presence of entero-pathogens in water environments.

The use of the coliform group, and more specifically E. coli, as an indicator of microbiological water quality dates from their first isolation from faeces at the end of the 19th century. Coliforms are also routinely found in diversified natural environments, as some of them are of telluric origin, but drinking water is not a natural environment for them. Their presence in drinking water must at least be considered as a possible threat or indicative of microbiological water quality deterioration. The use of the coliform group as an indicator of the possible presence of enteric pathogens in aquatic systems has been a subject of debate for many years. Many authors have reported waterborne disease outbreaks in water meeting the coliform regulations (Gofti et al., 1999).

Bacteria of the Enterobacteriaceae are important pathogens causing intestinal and systemic illness of humans and other animals. Consumption of water polluted with fecal material is an important exposure pathway, and while monitoring of total coliforms is the standard technique, some research suggests that analysis for E. coli specifically may be a better indicator (Baudisova, 1997). According to the U.S. Environmental Protection Agency (EPA) E.coli recommended indicator organisms for freshwater systems and is a sensitive measure of fecal pollution since it is common to almost all warm-blooded animals, including human. It is the microbiological parameter that is most frequently monitored in drinking water and bathing water surveillance. This bacterium resides in high numbers in the intestines of warm blooded animals and has proven its value to detect faecal contamination in water (Organization for Economic Cooperation and Development (OECD), 2003). Rapid methods to detect E. coli are important to identify the source of outbreaks and to assure public safety.

Objectives of the study:-

$\checkmark$ Collection of water samples from different places

$\checkmark$ Determination of Total Dissolved Solids (TDS) of water.

$\checkmark$ Determination of Dissolved Oxygen (DO) of water.

$\checkmark$ Determination of Biochemical Oxygen Demand (BOD) of water.

$\checkmark$ Determination of Chemical Oxygen Demand (COD) of water.

$\checkmark$ Determination of Acidity of water

$\checkmark$ Determination of Total Alkalinity of water.

$\checkmark$ Determination of Chlorine in water.

$\checkmark$ Determination of total bacterial population by Standard Plate Count (SPC) technique.

$\checkmark$ Detecting the presence of coliforms in water using Multiple tube fermentation (MPN) test 
$\checkmark$ Confirming the presence of bacteria from Enterobacteriaceae family using IMViC test.

$\checkmark$ Comparing the results with Indian Standard Institute (ISI) specification for drinking water

$\checkmark$ Comparing the results with Central Pollution Control Board (CPCB) standards for discharge of treated waste water (effluents)

\section{Materials and methods:-}

Sample collection:-

The water samples were collected from the different areas of Sree Sankara Vidhyapeetom. College, which is situated in a rural area of Ernakulam district.

\section{Determination of tds of water}

Water, the universal solvent, has a large number of salts dissolved in it which largely govern the physico-chemical properties of water and in turn have an indirect effect flora and fauna. Total dissolved solids (TDS) are determined as the residue left after evaporation of the filtered sample.

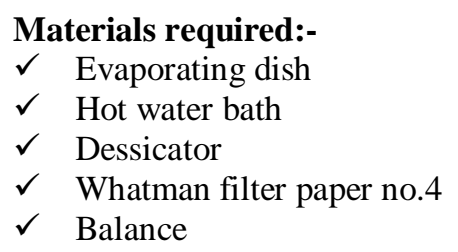

Procedure:-

- Take the weight of the evaporating dish

- Filter the sample of suitable quantity $(250-500 \mathrm{ml})$ through Whatman filter paper no.4

- Transfer the sample to evaporating dish

- Evaporate on a waterbath.

- Note the weight of the dish along with the contents after cooling in a desiccators.

\section{Determination of do of water:-}

The dissolved oxygen (DO) of water is important to all living organisms and is considered to be the lone factor which can reveal the nature of the whole aquatic system at a glance. The presence of DO in water may be attributed to two phenomena:- 1) direct diffusion from air, which is a physical process and depends on solubility of the oxygen under the influence of temperature, salinity, water movements etc and 2) photosynthetic evolution by aquatic autotrophs, which is a biological process and depends on the availability of light and the rate of metabolic processes resulting in diurinal fluctuations. The estimation of DO is done by the titrimetric method. The oxygen of the water combines with manganous hydroxide, which on acidification liberates iodine equivalent to that of oxygen fixed. This iodine is titrated by standard sodium thiosulphate solution using starch as indicator.

\section{Materials required:-}

$\checkmark$ Water sample

$\checkmark$ Pipette $(2 \mathrm{ml})$

$\checkmark$ Sodium thiosulphate

$\checkmark$ Manganous sulphate solution

$\checkmark$ Starch indicator

$\checkmark$ Sulphuric acid

$\checkmark$ Alkaline iodide-azide solution

$\checkmark$ Narrow mouth 250ml BOD bottle

$\checkmark$ Titration assembly

\section{Procedure:-}

- Collect water sample without bubbling in the $250 \mathrm{ml}$ glass bottle.

- Add $2 \mathrm{ml}$ each of manganous sulphate and alkaline iodide-azide solutions in succession, right at the bottom of the bottle with separate pipettes and replace the stopper.

- Shake the bottle in the upside down direction atleast six times. 
- Allow the brown precipitates to settle.

- Add $2 \mathrm{ml}$ of conc. Sulfuric acid and shake the stoppered bottle to dissolve the brown precipitates.

- Take $50 \mathrm{ml}$ sample in a flask and titrate with thiosulphate solution (taken in burette) till colour changes to pale straw.

- Add 2 drops of starch solution to the above flask which changes the colour of the contents from pale to blue.

- Titrate again with thiosulphate solution till blue colour disappears.

\section{Determination of bod of water:-}

The Biochemical Oxygen Demand (BOD) ia a way of expressing the amount of organic compounds in sewage as measured by the volume of oxygen required by bacteria to metabolize it under aerobic conditions. It is a good index of the organic pollution. If the amount of organic matter in sewage is more, the more oxygen will be utilized by bacteria to degrade it. Dumping sewage that contains high BOD increases the concentration of soluble organic compounds in the aquatic body where it is discharged. Digestion of these organic compounds in natural ecosystems, such as lakes, rivers, can deplete available oxygen and result in asphyxiation (death) of fish. The BOD of a water sample is generally measured by incubating the sample at $20^{\circ} \mathrm{C}$ for five days in the dark under aerobic conditions $\left(\mathrm{BOD}_{5} 20^{\circ} \mathrm{C}\right)$.

\section{Materials required:-}

- BOD free water

- BOD bottles

- Erlenmeyer flask

- Pipette

- BOD incubator

- $\mathrm{pH}$ meter

- Phosphate buffer solution

- Sulphuric acid

- Allythiourea solution

- Sodium hydroxide

- Reagents for DO estimation

\section{Procedure:-}

$\checkmark$ Adjust the $\mathrm{pH}$ of the water sample to neutrality using $1 \mathrm{~N}$ acid or $1 \mathrm{~N}$ alkali solutions.

$\checkmark$ Fill the water sample in 6 BOD bottles without bubbling.

$\checkmark$ Add $1 \mathrm{ml}$ of allythiourea to each bottle.

$\checkmark$ Determine dissolved oxygen content in three of the 6 BOD bottles by the titration method (as done earlier)

$\checkmark$ Take the mean of the three readings $\left(\mathrm{D}_{1}\right)$

$\checkmark$ Incubate the rest of the three BOD bottles at $27^{\circ} \mathrm{C}$ in a BOD incubator for 3 days.

$\checkmark$ Estimate the oxygen concentration in all three incubated samples.

$\checkmark$ Take the mean of three readings $\left(D_{2}\right)$

\section{Determination of cod of water:-}

In recent times, with the increase of pollution by discharging large amounts of various chemically oxidizable organic substances of different nature entering the aquatic systems, BOD alone does not give a clear picture of the organic matter content of the water sample. In addition, the presence of various toxicants in the sample may severely affect validity of the BOD test. Hence chemical oxygen demand (COD) is better estimate of the organic matter, which needs no sophistication and is time saving. However, COD, ie; the oxygen consumed (OC) does not differentiate the stable organic matter from the unstable form. Therefore, the COD values are not directly comparable to that of BOD.

The amount of organic matter in water is estimated by their oxidability by chemical oxidant such as potassium permanganate or potassium dichromate (the constituent carbon and hydrogen are oxidized and not the nitrogen). In the permanganate method, the organic matter is first oxidized with a known volume of $\mathrm{KMnO}_{4}$ and then the excess of oxygen is allowed to react with potassium iodide to liberate iodine in amounts equal to the excess oxygen, which is estimated titrimetrically with sodium thiosuphate solution using starch as an indicator.

Materials required:- 
- Water sample

- Potassium dichromate solution

- Sodium thiosulphate

- Sulphuric acid

- Potassium iodide solution

- Starch solution

- Water bath

- Titration assembly

- Conical flasks (100ml)

- Water blanks

\section{Procedure:-}

$\checkmark$ Take three $100 \mathrm{ml}$ conical flasks and pour $50 \mathrm{ml}$ of water sample in each. (in triplicate)

$\checkmark$ Simultaneously run distilled water blanks standards. (also in triplicate)

$\checkmark$ Add $5 \mathrm{ml}$ of potassium dichromate solution in each of the six flasks.

$\checkmark$ Keep the flasks in waterbath at $100^{\circ} \mathrm{C}$ for one hour.

$\checkmark$ Allow the samples to cool for 10 minutes.

$\checkmark$ Add $5 \mathrm{ml}$ of potassium iodide in each flask.

$\checkmark$ Add $10 \mathrm{ml}$ of sulphuric acid in each flask.

$\checkmark$ Titrate the contents of each flask with $0.1 \mathrm{M}$ sodium thiosulphate until the appearance of pale yellow colour.

$\checkmark$ Add $1 \mathrm{ml}$ of starch solution to each flask (solution turns blue)

$\checkmark$ Titrate it again with $0.1 \mathrm{M}$ Sodium thiosulphate until the blue colour disappears completely.

\section{Determination of acidity of water:-}

The acidity of water is its capacity to neutralize hydroxyl ions. Acidity may be caused by mineral acids such as sulphuric acid or hydrochloric acid or by dissolving carbon dioxide. Acidity increases the corrosive behaviour of water. Generally measured by titration with $\mathrm{NaOH}$ to an accepted $\mathrm{pH}$ value. Phenolphthalein is an acid-base indicator which changes from colourless to pink at a pH of 8.3. If a water sample is at the alkaline colour of the indicator before any titrant is added then the acidity is zero and the alkalinity of water should be tested.

\section{Materials required:-}

- Carbon dioxide free Water

- Standard sodium hydroxide titrant

- Phenolphthalein indicator

- Titration assembly

- Conical flasks (100ml)

\section{Procedure}

$\checkmark 100 \mathrm{ml}$ of water sample was taken in a $250 \mathrm{ml}$ conical falsk

$\checkmark$ Added 2-3 drops of phenolphthalein indicator

$\checkmark \quad$ The sample was then titrated with $0.025 \mathrm{~N}$ sodium hydroxide until the pink colour appears and end point was noted.

\section{Determination of total alkality of water:-}

Generally $\mathrm{pH}$ of water remains neutral. Alkalinity of water represents the presence of hydroxyl ions $(-\mathrm{OH})$ in water; hence, it is capacity of water to neutralize a strong acid. In natural or waste water alkalinity is due to the presence of free hydroxyl ions which cause through hydrolysis of salts by weak acids and strong bases (eg: carbonate and bicarbonates)

\section{Materials required:-}

- Conical flask (100ml)

- Water sample

- Titration assembly

- $\mathrm{HCl}$ solution

- Sodium carbonate solution 
- Phenolphthalein indicator

- Methylene orange indicator

Procedure:-

$\checkmark \quad$ Take $50 \mathrm{ml}$ of water sample in a conical flask.

$\checkmark$ Add few drops of Phenolphthalein indicator. If colour of water does not change, it means that phenolphthalein alkalinity (PA) is nil due to absence of carbonates in the water sample. Moreover, if there develops pink colour, determine PA.

$\checkmark$ Pour $0.1 \mathrm{~N} \mathrm{HCl}$ solution in burette and titrate with water sample. Note the end point when pink colour becomes colourless.

$\checkmark \quad$ Take another $50 \mathrm{ml}$ of water sample in flask and add 2-3 drops of methyl orange into it. Colour turns to orange.

$\checkmark$ Transfer $0.1 \mathrm{~N} \mathrm{HCl}$ solution into burette in titration assembly and titrate with the water sample (methylene orange added) until yellow colour changes to pink. Note the end point.

\section{Determination of chlorine in water:-}

The potable water is chlorinated to make the water free from microorganisms. However, sometimes the concentration of chloride ions in water is increased than what is normally required. A part from this water also receives chloride ions from multifarious sources. The chloride ions $\left(\mathrm{Cl}^{-}\right)$can be estimated by titrating with silver nitrate solution.

\section{Materials required:-}

- Conical flask

- Water sample

- Pipette

- Titration assembly

- Silver nitrate solution

- Potassium dichromate solution

\section{Procedure:-}

$\checkmark$ Take $50 \mathrm{ml}$ of sample in a conical flask and add $2 \mathrm{ml}$ of $\mathrm{K}_{2} \mathrm{Cr}_{2} \mathrm{O}_{7}$ solution.

$\checkmark$ Pour $0.025 \mathrm{~N}$ silver nitrate solution into burette set with titration assembly.

$\checkmark \quad$ Titrate the water sample with silver nitrate solution until reddish tinge appears. Note the end point. Silver nitrate reacts with chloride ions and forms very slightly soluble white precipitate of silver chloride. Free silver ions react with chromate ions to form silver chromate of reddish brown colour.

\section{Determination of total bacterial population by standard plate count technique (spc):-}

Plate count technique is useful in determining the efficiency of operations for removing or destroying organisms as during sedimentation filtration or chlorination. A microbial count can be made before and after a specific treatment and results obtained indicate the degree to which the bacterial population has been reduced. A water sample containing less than 100 bacteria per millilitre is considered to be of good quality. A total bacterial count is made by calculating the number of colonies appearing per tryptone glucose extract agar plates incubated at $20^{\circ} \mathrm{c}$ and $37^{\circ} \mathrm{c}$ for 72 and 24 hours respectively to which aliquots of water sample are added.

\section{Materials required:-}

- Water sample

- $\quad$ Sterile Pipette $(1 \mathrm{ml})$

- Tryptone glucose extract agar

- $\quad$ Sterile petri plates (4)

- Sterile $250 \mathrm{ml}$ glass bottle fitted with a glass stopper

\section{Procedure:-}

Collection of water sample

1) Hold the bottle near the base of the aquatic body with left hand and stopper removed with fingers of the right hand. 
2) Plunge the bottle neck downwards, below the water surface which is later tilled upwards towards the water current.

3) Remove the bottle from the water and replace the stopper and aluminium-foil cover.

4) Take the sample to the laboratory within 3 hours for examination (if delayed it should be packed in ice)

$\checkmark \quad$ Label the four sterile petri plates with the sample amount, ie. Two with $1 \mathrm{ml}$ and another two with $0.1 \mathrm{ml}$.

$\checkmark$ Mix the water sample thoroughly by shaking vigorously.

$\checkmark$ Pour $1 \mathrm{ml}$ of the sample each to appropriate sterile labelled plates using $1 \mathrm{ml}$ sterile pipette.

$\checkmark$ Pour $0.1 \mathrm{ml}$ of sample to two another labelled plates.

$\checkmark$ Add melted and cooled $\left(45-50^{\circ} \mathrm{C}\right)$ tryptone glucose agar or nutrient agar medium to the inoculated plates and mix the inoculum by rotating the plates for the uniform distribution of organisms.

$\checkmark$ Incubate one set of plates at $20-22^{\circ} \mathrm{C}$ for 72 hours and second set at $37^{\circ} \mathrm{C}$ for 24 hours.

\section{Determination of most probable number (mpn) or multiple tube fermentation test}

MPN test is the most oftenly used technique for the sanitary analysis of water. The test is used to detect coliforms (coliforms are defined as facultatively anaerobic, gram-negative, non-sporing, rod-shaped bacteria that ferment lactose with the production of acid and gas within $24 \mathrm{hrs}$ of incubation at $35^{\circ} \mathrm{C}$ ) that make up approximately $10 \%$ of the intestinal microorganisms of humans and other animals and have found widespread use as indicator organisms of fecal contamination.

The test is performed sequentially in three stages: presumptive, confirmed and completed test. Lactose broth tubes are inoculated with different water volumes in the presumptive test. Tubes that are positive for gas production are inoculated into brilliant green lactose bile broth in the confirmed test and positive tubes are used to calculate the MPN of coliforms in the water sample following the statistical table. The completed test, involving the inoculations of EMB agar plate, nutrient agar slant and brilliant green lactose bile broth and preparation of Gram satin slide from NA slant, is used to establish that coliform bacteria are present in the sample. The complete process, including the confirmed and completed tests requires at least 4 days of incubation and transfers.

\section{Presumptive test:-}

The presumptive test is specific for the detection of coliform bacteria. In this test known volume of water is added to the Mac Conkey broth tubes containing an inverted Durham's tube. The production of gas and acid as result of lactose fermentation is a positive indication for the presence of coliform bacteria. The Mac Conkey broth used in this test is selective for the isolation of coliform due to the addition of bile. The bile salt is added to suppress the growth of organism other than coliform bacteria. For the detection of acid production a $\mathrm{pH}$ indicator such as neutral red is added which turns pink on fermentation of lactose. A statistical method is used to estimate the population of coliforms so that the result obtained is expressed as the most probable number of coliforms. After incubation period the lactose fermenting tubes with gas and acid production are counted and MPN is found by comparing the result with those provided in the statistical table.

\section{Materials required:-}

- Water sample

- Mac Conkey broth (single and double strength)

- Durhams tube

- $\quad$ Sterile pipettes $(10 \mathrm{ml}, 1 \mathrm{ml}, 0.1 \mathrm{ml})$

\section{Procedure}

$\checkmark$ Collected water samples

$\checkmark$ Labelled three double strength MacConkey Broth tubes "10" and three single strength broth " 1 " and another single strength three tubes " 0.1 " for each sample.

$\checkmark$ Mixed each of the water sample by thorough shaking

$\checkmark$ Aseptically inoculated each " 10 " tubes with $10 \mathrm{ml}$ of water sample using

$\checkmark$ a $10 \mathrm{ml}$ sterile pipette

$\checkmark$ Using a1 $1 \mathrm{ml}$ sterile pipette aseptically inoculated the three single strength tubes (labelled as " 1 ") with $1 \mathrm{ml}$ water

$\checkmark \quad$ Using a $0.1 \mathrm{ml}$ sterile pipette, aseptically inoculated the three single strength tubes (labelled as " 0.1 ") with $0.1 \mathrm{ml}$ water sample

$\checkmark$ Inoculated all the tubes aerobically at $37^{0} \mathrm{C}$ for 48 hours 


\section{Confirmed test:-}

It is used to establish the presence of coliform bacteria and as a confirmatory test for the presence of E.coli in a water sample. The samples from the positive brilliant green lactose bile broth from the confirmed test streaked onto a selective differential medium for coliforms and inoculated into lactose broth tube as well as streaked on a nutrient agar plate to perform Gram-staining. The medium commonly used is Eosin Methylene Blue (EMB) which inhibits the growth of gram positive bacteria, allowing the growth of gram negative bacteria. EMB medium is differential in nature as lactose fermenting bacteria gives coloured colonies. In the presence of acid environment, EMB forms a complex that precipitate out onto the coliform colonies, producing dark centers and a green metallic sheen. Nonlactose fermenters produce colourless colonies on EMB agar. If there is production of acid and gas in the inoculated lactose broth and there are rod shaped bacteria showing Gram-negative reaction. This reaction is characteristic for $E$ coli, the major indicator of fecal pollution and is considered a positive completed test.

\section{Materials required:-}

- EMB agar plates

- 24 hrs old positive broth culture from presumptive test

- Inoculating loop

- Bunsen burner

\section{Procedure:-}

$\checkmark \quad$ Inoculated the EMB agar plates with positive presumptive broth culture with sterile inoculation loop

$\checkmark \quad$ Incubated the plates for $24 \mathrm{~h}$ at $37^{\circ} \mathrm{C}$ in an inverted position

\section{Completed test:-}

The completed test is the final analysis of water sample. It is used to examine the coliform colonies that appeared on the EMB agar plates used in the confirmed test. An isolated colony is picked from the confirmatory test plate and inoculated into a tube of lactose broth and streaked on a nutrient agar slant to perform a gram stain. Following inoculation and incubation, tubes showing acid and gas in the lactose broth and presence of gram negative Bacilli on microscopic examination, further confirmed the presence of E.coli and they are indicative of a positive completed test.

\section{Materials required:-}

- Nutrient agar plates

- 24 hrs old positive broth culture from presumptive test

- Inoculating loop

- Bunsen burner

- Lactose fermentation broth

- Gram staining reagents.

\section{Procedure:-}

$\checkmark$ Inoculated lactose fermentation broth with isolated coliform colony from EMB agar plates

$\checkmark$ Streaked the sample colony onto nutrient agar slant.

$\checkmark \quad$ Incubated the broth and slants at $37^{\circ} \mathrm{C}$ for $24 \mathrm{hrs}$.

$\checkmark$ The colonies stained on slants are subjected to gram staining.

\section{Confirming The presence of bacteria from enterobacteriaceae family using imvic test:-}

The IMViC tests consist of four different tests: 1) Indole production; 2) Methyl-red; 3) Voges-Proskauer; and 4) Citrate utilization. The name IMViC stands for the first letter of the name of each test in the series, with the lower case "i" included for ease of pronounciation. The IMViC tests were designed to differentiate gram negative intestinal bacilli (family Enterobacteriaceae) particularly Escherichia coli and the Enterobacter-Klebsiella group, on the basis of their biochemical properties and enzymatic reactions in the presence of specific substrates.

\section{Indole production test :-}

Indole production test is used to determine the ability of microorganism to degrade amino acid tryptophan. 


\section{Principle:-}

Ability to dehydroxylase tryptophan with production of indole is not a characteristic of all microorganisms and therefore these serves as a biochemical marker. The presence of indole is detected by adding Kovacs reagent; which produces a cherry red reagent layer. This colour is produced by the reagent which is composed of a p-dimethyl amino benzaldehyde, butanol and $\mathrm{HCl}$. Indole is extracted from the medium into the reagent layer by the acidified butanol component and forms a complex with p-dimethyl amino benzaldehyde giving the cherry red colour.

\section{Materials required:-}

- 14-18 hour old culture

- Bunsen burner

- Inoculating loop

- Kovac's reagent

\section{Procedure:-}

$\checkmark$ Inoculated tryptone broth with culture and one uninoculated broth served as blank

$\checkmark$ Incubated the tubes at $35^{\circ} \mathrm{C}$ for 48 hours

$\checkmark$ After 48 hours of incubation added $1 \mathrm{ml}$ of Kovacs reagent to each tube including control

$\checkmark$ The tubes were gently mixed after intervals for 10-15minutes. Allowed the tubes to stand to permit the reagent to come to the top. Examined the tubes for the colour of the top layer

\section{Methyl red test:-}

Methyl red test is used to determine the ability of microorganisms to oxidize glucose with production and stabilization of high concentration of acid end product.

\section{Principle:-}

In this test $\mathrm{pH}$ indicator methyl red detects the large concentration of acid product. Although all enteric microorganisms ferment glucose with production of organic acid, this test is valid for separation of E.coli and Enterobacter aerogenes. Methyl red indicator in the range of $\mathrm{pH} 4$ will turn red which is indicative of positive test. Evolution of $\mathrm{pH} 6.0$ will result in yellow colour (negative test).

\section{Materials required:-}

- 24hour old culture

- GPP broth

- Methyl red indicator

\section{Procedure:-}

$\checkmark$ Using sterile techniques, inoculated each organism into its appropriately labelled tube of medium by means of loop inoculation.

$\checkmark \quad$ Incubate all cultures for $24-48 \mathrm{~h}$ at $37^{\circ} \mathrm{C}$.

\section{Vogues proskaeur test:-}

This test is used to differentiate enteric organisms such as E.coli, Enterobacter aerogens, Klebsiella

\section{Principle:-}

The Vogeus Proskaeur test determines the capacity of some organisms to produce non acidic and neutral products such as acetyl methyl carbinol from organic acid that result from fermentation of glucose. A pink complex is formed, giving a rose colour to the medium.

\section{Materials required:-}

- $\quad 24-48$ hour old culture

- Barrit's reagent

- GPP broth 
Procedure:-

$\checkmark$ Transfered approximately $1 / 3$ of each culture into an empty test tube.

$\checkmark$ Added 6 drops of Barrit's reagent.

$\checkmark$ Incubated all the tubes for $24-48$ hours at $37^{\circ} \mathrm{C}$.

\section{Citrate utilization test:-}

It is used to differentiate among enteric organisms on basis of their ability to ferment citrate as a sole carbon source.

\section{Principle:-}

Citrate is acted upon by the enzyme citrase, which produces oxalic acid and acetate. These products are enzymatically converted to pyruvic acid and carbon dioxide. During this reaction, the medium becomes alkaline. The carbondioxide that is generated combines with sodium and water to form sodium carbonate, an alkaline product. The presence of sodium carbonate changes the bromothymol blue indicator, incorporated into the medium from green to deep purssion blue. Citrate positive culture is identified by the presence of growth on the surface of slant, which is accomplished by blue colouration. Citrate negative culture will show no growth and the media remain green.

\section{Materials required:-}

- Broth culture

- Simmon's citrate agar slants

- Bunsen burner

- Inoculating loops

Procedure:-

$\checkmark$ Inoculated Simmons citrate agar slants by means of a stab and streak inoculation.

$\checkmark$ One uninoculated slant served as control.

$\checkmark$ All the slants are incubated at $37^{\circ} \mathrm{C}$ for 48 hours.

$\checkmark$ Observed the slant cultures for growth and colouration of medium

\section{Isi (indian standard institute) specification for drinking water:-}

Life is possible because of water; hence, use of water of good quality makes healthy life. However, physicochemical and biological properties of water vary with sources of water, types of water and geographical regions. There are certain chemicals present in water in higher or lower amount than the required ones. Similarly, there are a number of pathogenic water-borne protozoa, fungi, bacteria, and viruses present in water.

The samples taken from the distribution system should be free from coliform organisms. Throughout the year $95 \%$ samples should not contain any coliform organisms. However, if any coliform is found immediate resampling should be done. In addition, no sample should contain E.coli in $100 \mathrm{ml}$ of samples taken randomly from anywhere. Thus, the presence of these organisms in water makes the quality poor and unhygienic. ISI specification for drinking water (potable water) has been given in Table below:

Table:- ISI specification for drinking water.

\begin{tabular}{|l|c|l|l|}
\hline Characteristics & Desirable limits & $\begin{array}{l}\text { Undesirable effect after the } \\
\text { desirable limit }\end{array}$ & Remark \\
\hline \multicolumn{5}{|c|}{ Microbial Characteristics } \\
\hline Coliforms (cfu/100ml) & $1-10$ & $\begin{array}{l}\text { No sample should contain more } \\
\text { than 10coliforms per 100 ml } \\
\text { sample }\end{array}$ & $\begin{array}{l}\text { To be tested when } \\
\text { pollution is } \\
\text { suspected. }\end{array}$ \\
\hline E.coli & $\begin{array}{l}\text { No sample should contain } \\
\text { E.coli in 100 ml. Otherwise } \\
\text { gastrointestinal infection will } \\
\text { be caused. }\end{array}$ & $\begin{array}{l}\text { To be tested when } \\
\text { pollution is } \\
\text { suspected. }\end{array}$ \\
\hline 0 & $\begin{array}{l}\text { Essential Characteristics } \\
\text { (mg/l, Maximum limit) }\end{array}$ \\
\hline
\end{tabular}




\begin{tabular}{|c|c|c|c|}
\hline $\begin{array}{l}\text { Colour (Hazen units, } \\
\text { Max.) }\end{array}$ & 5 & $\begin{array}{l}\text { After } 5 \text { consumer's acceptance } \\
\text { decreases }\end{array}$ & $\begin{array}{l}\text { for non-toxic } \\
\text { substances. }\end{array}$ \\
\hline Odour & Un-objectionable & - & $\begin{array}{l}\text { Test cold and } \\
\text { when heated }\end{array}$ \\
\hline Taste & Agreeable & - & $\begin{array}{l}\text { Test after } \\
\text { establishing safety }\end{array}$ \\
\hline Turbidity (NTS) & 5 & $\begin{array}{ll}\text { Consumer's } & \text { acceptance } \\
\text { decreases after } 5\end{array}$ & - \\
\hline $\mathrm{pH}$ value & 6.5 to 8.5 & $\begin{array}{l}\text { Thereafter, mucous membrane } \\
\text { affected. }\end{array}$ & - \\
\hline Chloride (as Cl) & 250 & $\begin{array}{l}\text { Taste, corrosion } \\
\text { palatability are affected }\end{array}$ & - \\
\hline \multicolumn{4}{|c|}{ Desirable Characteristics } \\
\hline Dissolved Solids & 500 & $\begin{array}{l}\text { Palatability decreases and may } \\
\text { cause gastro-intestinal irritation }\end{array}$ & - \\
\hline Alkalinity & 200 & $\begin{array}{l}\text { Beyond this limit taste become } \\
\text { unpleasant }\end{array}$ & - \\
\hline
\end{tabular}

Cpcb (central pollution control board) standards for discharge of treated waste water (eefluents):-

\begin{tabular}{|c|c|c|c|c|}
\hline \multirow[t]{2}{*}{ Parameters } & \multicolumn{4}{|c|}{ Standards } \\
\hline & $\begin{array}{c}\text { Inland surface } \\
\text { water }\end{array}$ & Public sewers & Land for irrigation & $\begin{array}{l}\text { Marine coastal } \\
\text { areas }\end{array}$ \\
\hline \multicolumn{5}{|c|}{ Physical parameters } \\
\hline $\begin{array}{l}\text { Suspended solids } \\
\text { (mg/l, max) }\end{array}$ & 100 & 600 & 200 & $\begin{array}{l}100 \text { for process } \\
\text { water }\end{array}$ \\
\hline $\begin{array}{l}\text { Size of suspended } \\
\text { solids }\end{array}$ & $\begin{array}{l}\text { Shall pass through } \\
850 \text { micron sieve }\end{array}$ & - & - & $\begin{array}{c}\text { Floatable solid } 3 \\
\text { mm; settleable solid } \\
850 \text { micron }\end{array}$ \\
\hline Temperature & $\left\langle 5^{\circ} \mathrm{C}\right.$ & - & - & $\left\langle 5^{\circ} \mathrm{C}\right.$ \\
\hline \multicolumn{5}{|c|}{ Biological parameters } \\
\hline Bioassay test & $\begin{array}{l}90 \% \text { survival of fish } \\
\text { after } 96 \text { hours in } \\
100 \% \text { effluent }\end{array}$ & $\begin{array}{l}90 \% \text { survival of fish } \\
\text { after } 96 \text { hours in } \\
100 \% \text { effluent }\end{array}$ & $\begin{array}{c}90 \% \text { survival of fish } \\
\text { after } 96 \text { hours in } \\
100 \% \text { effluent }\end{array}$ & $\begin{array}{l}90 \% \text { survival of fish } \\
\text { after } 96 \text { hours in } \\
100 \% \text { effluent }\end{array}$ \\
\hline \multicolumn{5}{|c|}{ Chemical parameters } \\
\hline $\mathrm{pH}$ & 5.5 to 9.0 & 5.5 to 9.0 & 5.5 to 9.0 & 5.5 to 9.0 \\
\hline $\begin{array}{c}\text { Total residual } \\
\text { chlorine }(\mathrm{mg} / \mathrm{l}, \mathrm{max})\end{array}$ & 1.0 & - & - & 1.0 \\
\hline $\begin{array}{c}\text { BOD (5days at } \\
\left.20^{\circ} \mathrm{C}\right)(\mathrm{mg} / \mathrm{l}, \mathrm{max})\end{array}$ & 30 & 350 & 100 & 100 \\
\hline $\mathrm{COD}(\mathrm{mg} / \mathrm{l}, \mathrm{max})$ & 250 & - & - & 250 \\
\hline
\end{tabular}

CPCB standards for discharge of effluents on land surface, public sewers, irrigation lands and marine coastal areas.

\section{Results:-}

The results of the study entitled "Checking the purity of water samples collected from a rural area and assuring the public safety by creating awareness to the people living in that area" undertaken at Postgraduate Department of Bioscience, SSV College, Ernakulam is as follows:-

The project work mainly included the following aspects:-

\section{Sample collection:-}

The samples were collected from the water bodies in and around SSV College, Valayanchirangara, Ernakulam. The locations of collection are given below:- 


\begin{tabular}{|l|l|}
\hline \multicolumn{1}{|c|}{ Sample No } & Location \\
\hline 1 & Kaiyanikkal canal \\
\hline 2 & Valayanchirangara temple pond \\
\hline 3 & Panchayath well \\
\hline 4 & Rainwater harvesting pits \\
\hline 5 & Kamrutha UP School well \\
\hline 6 & Vengola Canal \\
\hline 7 & Panchayat Water supply \\
\hline 8 & Vengola Pond \\
\hline 10 & Puluvazhy canal \\
\hline 11 & SSV college well \\
\hline 12 & Airapuram pond water \\
\hline
\end{tabular}

The following techniques were conducted respectively to check the purity of the water samples taken from different places of a rural area.

Total Dissolved Solids:-

TDS was determined as the residue left after evaporation of the filtered sample.

\begin{tabular}{|c|c|}
\hline Sample No & TDS (mg/L) \\
\hline 1 & 483.5 \\
\hline 2 & 570.3 \\
\hline 3 & 258 \\
\hline 4 & 833.02 \\
\hline 5 & 201.2 \\
\hline 6 & 737.5 \\
\hline 7 & 649.8 \\
\hline 8 & 621.5 \\
\hline 9 & 580.2 \\
\hline 10 & 421.8 \\
\hline 11 & 652.4 \\
\hline 12 & 674.1 \\
\hline
\end{tabular}

\section{DO, BOD and COD Values:-}

DO in the water sample was determined using titrimetric method. BOD, which is used as a parameter to express the strength of sewage by measuring the volume of oxygen required by bacteria to metabolize the organic compounds in sewage, was determined. COD, another technique which is more efficient to estimate the organic matter in water by using the oxidability of organic matter by a chemical oxidant such as potassium permanganate or potassium dichromate was determined.

\begin{tabular}{|c|c|c|c|}
\hline Sample No & DO (mg/L) & BOD(mg/L) & COD (mg/L) \\
\hline 1 & 44.3 & 40.1 & 184.2 \\
\hline 2 & 70.4 & 68 & 290.5 \\
\hline 3 & 30.12 & 28.1 & 44.8 \\
\hline 4 & 53.1 & 49.7 & 230.6 \\
\hline 5 & 31.1 & 29.2 & 36.5 \\
\hline 6 & 301.3 & 13 & 620.025 \\
\hline 7 & 190.4 & 54 & 320.06 \\
\hline 8 & 280.1 & 49 & 590.63 \\
\hline 9 & 222.25 & 43 & 480.32 \\
\hline 10 & 160.0 & 11 & 200 \\
\hline 11 & 190.1 & 20 & 300.4 \\
\hline 12 & 240.8 & 32 & 440.9 \\
\hline
\end{tabular}


Acidity, Alkalinity and Chlorine content

Acidity, Alkalinity and Chlorine content of each sample was also determined. The result is as follows:-

\begin{tabular}{|c|c|c|c|}
\hline Sample No & Alkalinity (mg/L) & Acidity (mg/L) & Chlorine content (mg/L) \\
\hline 1 & 180.6 & 10.5 & 280.5 \\
\hline 2 & 230.4 & 18 & 490.2 \\
\hline 3 & 90 & 10 & 150 \\
\hline 4 & 320.5 & 30.2 & 630.06 \\
\hline 5 & 40 & 9 & 100 \\
\hline 6 & 65.7 & 63 & 209.1 \\
\hline 7 & 59.1 & 57.4 & 210.3 \\
\hline 8 & 62.8 & 59.1 & 294.2 \\
\hline 9 & 50.9 & 48.1 & 105 \\
\hline 10 & 29.8 & 27.2 & 49.2 \\
\hline 11 & 52.1 & 50.27 & 160 \\
\hline 12 & 42.3 & 39.41 & 240.5 \\
\hline
\end{tabular}

Standard plate count method:-

SPC was done, which is one of the routine procedures to determine the number of microbes in water. A water sample containing less than 100 bacteria per millilitre is considered to be of good quality. A total bacterial count is made by calculating the number of colonies appearing per tryptone glucose extract agar plates incubated at $20^{\circ} \mathrm{C}$ and $37^{\circ} \mathrm{C}$ for 72 and 24 hours respectively to which aliquots of water sample are added.

Most of the culture was TNTC (Too numerous to be counted). Samples 3, 5, 10 give a countable number range. Indicating that the water samples were highly contaminated.

Multiple tube fermentation tests:-

The purity of drinking water was evaluated by testing for the presence of coliforms, which is an indicator of fecal contaminations. It was done by using MPN analysis.

\section{Presumptive test:-}

All the tubes were examined for the production of acid and gas after 24h and 48h of incubation. The MPN is found by comparing the result with those provided in the statistical table. From the MPN test, it was observed that all the samples were positive for coliform bacteria.

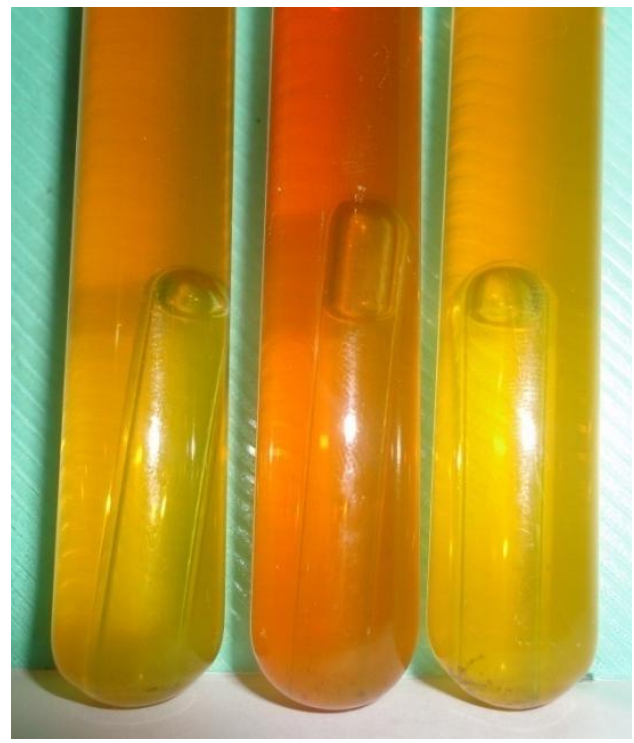

MPN Positive Tubes. 


\begin{tabular}{|c|c|c|c|c|c|}
\hline \multirow[t]{3}{*}{ Sample No } & \multicolumn{3}{|c|}{ Number of tubes showing positive result } & \multirow[t]{3}{*}{ Reading } & \multirow{3}{*}{$\begin{array}{l}\text { MPN Index } \\
\text { per } 100 \mathrm{ml}\end{array}$} \\
\hline & Double strength & Single strength & Single strength & & \\
\hline & $10 \mathrm{ml}$ & $1 \mathrm{ml}$ & $0.1 \mathrm{ml}$ & & \\
\hline 1 & +++ & +++ & ++- & 332 & 1100 \\
\hline 2 & +++ & +++ & +++ & 333 & 2400 \\
\hline 3 & +-- & --- & --- & 100 & 4 \\
\hline 4 & +++ & ++- & +-- & 321 & 150 \\
\hline 5 & +-- & --- & --- & 100 & 4 \\
\hline 6 & +++ & +++ & +++ & 333 & 2400 \\
\hline 7 & ++- & ++- & -- & 220 & 21 \\
\hline 8 & +++ & +++ & +++ & 333 & 2400 \\
\hline 9 & ++- & ++- & +-- & 221 & 28 \\
\hline 10 & +- & -- & -- & 00 & 4 \\
\hline 11 & +++ & +++ & +++ & 333 & 2400 \\
\hline 12 & +++ & +++ & +-- & 331 & 460 \\
\hline
\end{tabular}

\section{MPN Index of the Water Samples Collected}

\section{Confirmed test :-}

The confirmed test was performed in the MPN positive samples. The samples were streaked in the EMB plates. The green metallic sheen was checked after 24 hour incubation at $37^{\circ} \mathrm{C}$.

\section{IMViC TEST:-}

Detection and confirmation of the presence of E.coli was done by using IMViC test.

\section{Indole production test:-}

Development of cherry (deep) red colour in the top layer of the tube was observed in all tubes. E.coli is positive for indole production.

\section{Methyl Red test:-}

The production of acid by fermentation was detected by methyl red indicator. Development of deep pink colour was observed in all the tubes. This test is positive for $E$ coli.

\section{Vogues Proskaeur test:-}

Development of pink to dark red colour is characteristic for positive VP test. Yellow or colourless tubes gave negative test. Klebsiella is VP positive and E.coli negative. The samples 1, 3, 5, 8, 11 and 12 gave positive result and samples 2, 4, 6, 7, 9 and 10 gave negative result for this test.

\section{Citrate utilization test:-}

The medium turning to blue is positive result for citrate utilization test. E.coli is negative for this test. No colour change was observed for the negative test. The samples 6, 7, 9, 10,11 and 12 gave positive result and samples 1,2, $3,4,5$ and 8 gave negative result for this test.

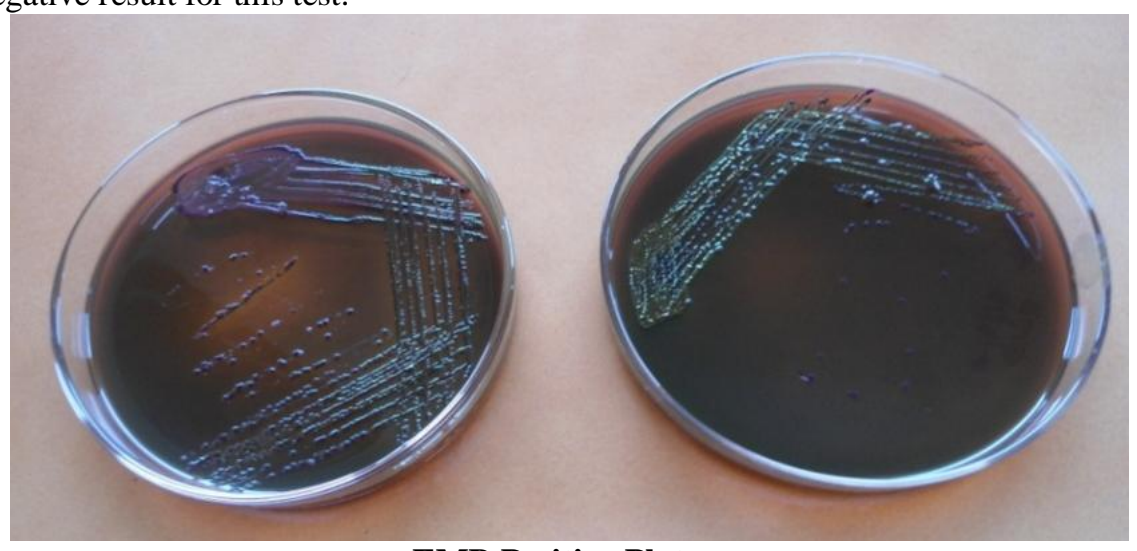

EMB Positive Plates. 


\begin{tabular}{|c|c|c|c|c|c|}
\hline Sample No & $\begin{array}{l}\text { Double } \\
\text { strength }\end{array}$ & Single strength & Single strength & Reading & $\begin{array}{l}\text { MPN } \\
\text { Index/100ml }\end{array}$ \\
\hline 1 & +-- & --- & --- & 100 & 4 \\
\hline 2 & +++ & ++- & --- & 320 & 93 \\
\hline 3 & --- & --- & --+ & 001 & 3 \\
\hline 4 & +-- & --- & --- & 100 & 4 \\
\hline 5 & --- & +-- & --- & 010 & 3 \\
\hline 6 & ++- & +-- & --- & 210 & 43 \\
\hline 7 & +-- & --- & --- & 100 & 4 \\
\hline 8 & ++- & --- & --- & 200 & 9 \\
\hline 9 & --- & -+- & --- & 100 & 3 \\
\hline 10 & +-- & --- & --- & 221 & 4 \\
\hline 11 & ++- & +-- & 001 & 28 \\
\hline 12 & --- & --- & & 3 \\
\hline
\end{tabular}

MPN Index of EMB plates

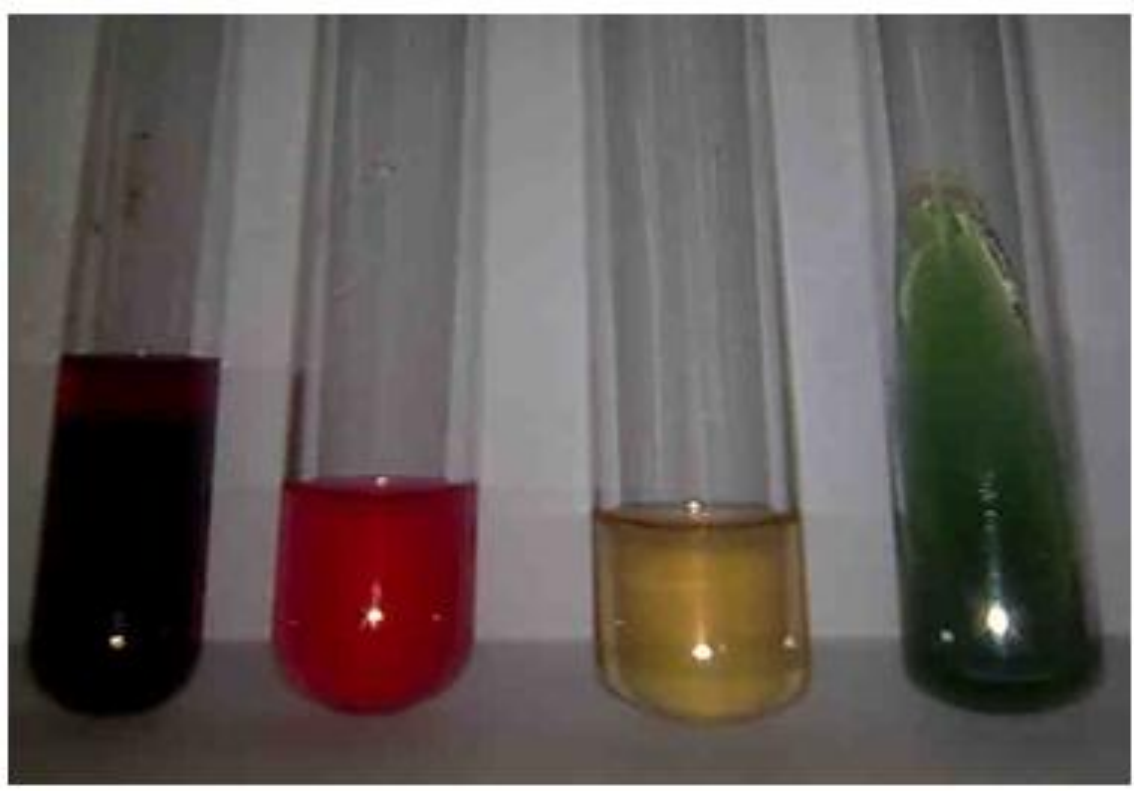

Samples which gave ++-- for the IMViC test was positive $E$ coli culture. From the IMViC test carried out, some samples were selected as the pure E.coli cultures. The IMViC test results are given below.

\begin{tabular}{|c|c|c|c|c|c|}
\hline Sample No & Indole Test & MR Test & VP Test & Catalase Test & E.coli Confirmed \\
\hline 1 & + & + & + & - & No \\
\hline 2 & + & + & - & - & Yes \\
\hline 3 & + & + & + & - & No \\
\hline 4 & + & + & + & - & Yes \\
\hline 5 & + & + & - & - & No \\
\hline 6 & + & + & - & + & No \\
\hline 7 & + & + & + & - & No \\
\hline 8 & + & + & - & + & No \\
\hline 9 & + & - & - & + & No \\
\hline 10 & + & + & + & + & No \\
\hline 11 & + & + & + & + & No \\
\hline
\end{tabular}

IMViC Test Results for Water Samples 


\section{Completed test :-}

The completed test was performed in the MPN positive samples. Gram staining was performed to confirm the presence of E.coli

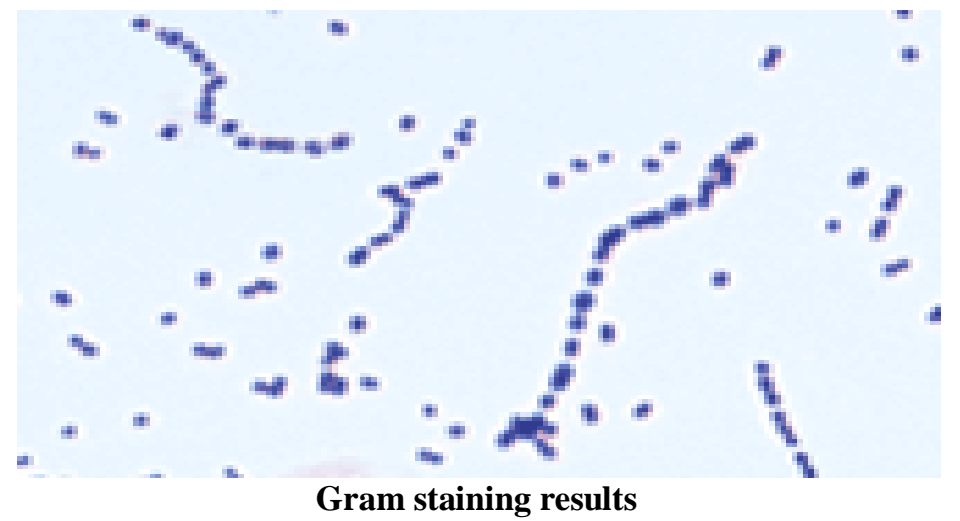

The overall results were compared with ISI specification and CPCB standard values for the discharge of treated water. The samples taken from the distribution system should be free from coliform organisms as per the given standards. The comparison revealed the fact that some water samples are highly contaminated and unsafe for proper use.

\section{Conclusion:-}

A number of traditional approaches for analysis of E. coli relied on cultural techniques. In this study, some cultural techniques and titration methods were used to check the purity of the water samples taken from different places of a rural area. The result of each test gives a preliminary report regarding the microbial contaminants present in the water samples. The IMViC test also confirmed the presence of $E$. coli cultures. Many workers have earlier reported the use of MPN and IMViC tests for the detection of microbial load in drinking water (Rompre et al, 2002; Jakee-El et al 2009). Water is essential to sustain life and a satisfactory supply must be made available to consumers. The right to potable water is nowadays, part of human rights. In industrialized countries drinking water is ranked as food and high standards are set for quality and safety. In developing countries 13 million people die and 1.1 billion people lack access to an improved water source. As a result of infectious diseases related to unsafe water an estimated 3 million people in developing regions of the world die each year. A common surveillance tool for waterborne pathogens is needed to reduce public health emergencies by standardizing methodologies and validation at international level.

\section{Bibliography:-}

1. AFNOR (Association Francaise de Normalisation). (1990), Eauxme'thodes d'essais. Recueil de Normes Francaises, 4th edn. La De'fense, Paris, 735 pp.

2. APHA, AWWA, AEF, 1998. Standard Methods for the Examination of Water and Wastewater, 20th edn.Washington, DC.

3. Baudisova D. (1997), Evaluation of Escherichia coli as the main indicator of faecal pollution. Water Sci. Techno; vol35:333-336.

4. Gofti L, Zmirou D, Murandi FS, Hartemann P and Poleton JL. (1999), Waterborne microbiological risk assessment: a state of the art and perspectives. Epidemiol. Sante' Publi; vol47: 61 - 75.

5. Jakee-El J, Moussa EI, Mohammed KF, Mohamed G. (2009), Using Molecular Techniques for Characterization of Escherichia coli Isolated from Water Sources in Egypt. Global Veterinaria; 3 (5): 354-362.

6. Pant PR. (2004), Tailored media for the detection of E. coli and coliforms in the water sample. Journal of Tribhuvan university; vol 24(1): 49-54.

7. Rompre A, Servais P, Baudart J, De- Roubin M and Laurent P. (2002)), Detection and enumeration of coliforms in drinking water: current methods and emerging approaches. Journal of Microbiological Methods; vol 49: 3154.

8. Simpson JM, Santo Domingo JW and Reasoner DJ. (2002), Microbial source tracking: state of the science. Environmental Science Technology; vol36(24): 5279-5288. 